\title{
ATRIOVENTRICULAR VALVE FUNCTION AFTER SINGLE PATCH REPAIR OF COMPLETE ATRIOVENTRICULAR SEPTAL DEFECT IN INFANCY: HOW EARLY SHOULD REPAIR BE ATTEMPTED?
}

\author{
V. Mohan Reddy, MD \\ Doff B. McElhinney, MS ${ }^{\mathrm{a}}$ \\ Michael M. Brook, MD ${ }^{\mathrm{b}}$ \\ Andrew J. Parry, MD ${ }^{\mathrm{a}}$ \\ Frank L. Hanley, MD
}

\begin{abstract}
Background: Though repair of complete atrioventricular septal defect in infancy has become routine at most centers, it is not unusual for very young infants to be managed medically because of concerns about the fragility of the atrioventricular valve tissue. Methods: Since July 1992, seventy-two infants have undergone primary repair of complete atrioventricular septal defects at a median age of 3.9 months $(40 \%<3$ months $)$. A single-patch technique was used in all patients. The cleft was closed completely in 61 patients and partially $(n=10)$ or not at all $(n=1)$ in select patients at risk for valve stenosis. Left atrioventricular valve annuloplasty was performed in 18 patients. On the basis of transesophageal echocardiographic findings, 10 patients were returned to bypass for revision of the valve repair. Results: There was one early death in a patient with single left papillary muscle, no early reoperations, and no new permanent arrhythmias. Only three patients had moderate left atrioventricular valve regurgitation at discharge. During a median follow-up of $\mathbf{2 4}$ months, there was one late death and five reoperations for left atrioventricular valve regurgitation $(n=2)$ and/or systemic outflow obstruction $(n=4)$. Follow-up left atrioventricular valve regurgitation was moderate in three patients, mild in 14, and none/trace in 54. Age had no relation to postoperative atrioventricular valve regurgitation, death, or reoperation. Conclusions: Despite concerns about fragility of valve tissue in very young patients, excellent results can be achieved with meticulous techniques. From neonates to older infants, age at repair does not influence outcome or valve function. (J Thorac Cardiovasc Surg 1998; 115:1032-40)
\end{abstract}

0 ver the past 10 to 20 years, primary repair of complete atrioventricular septal defect (AVSD) in infancy has become common practice at many institutions, ${ }^{1-6}$ and mortality over this period has decreased significantly. ${ }^{1-4}$ The primary concerns in the present era are how best to preserve atrioventricular (AV) valve function and reduce the need for reoperations on the left $\mathrm{AV}$ valve. In this context,

From the Divisions of Cardiothoracic Surgery ${ }^{\mathrm{a}}$ and Pediatric Cardiology, ${ }^{\mathrm{b}}$ University of California, San Francisco, Calif.

Read at the Seventy-seventh Annual Meeting of The American Association for Thoracic Surgery, Washington, D.C., May 4-7, 1997.

Received for publication May 12, 1997; revisions requested June 30, 1997; revisions received Oct. 27, 1997; accepted for publication Oct. 29, 1997.

Address for reprints: V. Mohan Reddy, MD, 505 Parnassus Ave., M589, San Francisco, CA 94143-0118.

Copyright (C) 1998 by Mosby, Inc.

$0022-5223 / 98 \$ 5.00+0 \quad \mathbf{1 2 / 6 / 8 7 2 2 2}$ the advantages and drawbacks of various surgical techniques, such as closure of the "cleft" of the left AV valve, and single versus double patch repair have been debated in the literature. ${ }^{1-8}$ There has been little focus on the relationship between age at repair in infancy and outcomes. ${ }^{5}$ Although repair before 6 months of age is common, medical therapy is generally used with neonates, very young infants, and low birth weight babies, primarily because of technical concerns about the fragility of the AV valve tissue. Delay of surgery in this setting often leads to increasing morbidity from respiratory infections, failure to thrive, damage to valve tissue from thickening and distortion, and development of pulmonary vascular disease. ${ }^{9}$ Since 1992 , we have taken the approach of completely repairing AVSD early in infancy rather than continuing with prolonged medical management. This experience provides the opportunity to review a large cohort of patients ranging in age from less than 1 month to older infancy in

1032 
Table I. Associated anomalies among 72 infants undergoing repair of complete AVSD

\begin{tabular}{lc}
\hline \multicolumn{1}{c}{ Associated anomalies } & $\begin{array}{c}\text { No. of } \\
\text { patients (\%) }\end{array}$ \\
\hline Left superior vena cava & $13(18)$ \\
To coronary sinus & $10(14)$ \\
To left atrium & $3(4)$ \\
Multiple ventricular septal defects & $7(9)$ \\
Unbalanced AVSDs & $7(9)$ \\
Tetralogy of Fallot & $6(8)$ \\
Severe AV valve dysplasia & $5(7)$ \\
Double-orifice left AV valve & $4(6)$ \\
Coarctation of the aorta & $4(6)$ \\
Interrupted inferior vena cava & $3(4)$ \\
Single left papillary muscle & $2(3)$ \\
Valvular pulmonary stenosis & $2(3)$ \\
Cor triatriatum & $1(1)$ \\
\hline
\end{tabular}

$A V S D$, Atrioventricular septal defect; $A V$, atrioventricular.

an attempt to elucidate the effects of repair in early infancy on overall outcomes, especially AV valve function.

\section{Patients and methods}

Patients. Between July 1992 and January 1997, 72 infants with complete AVSD underwent surgical repair. The median age was 3.9 months (range 28 days to 10.5 months). Patient weight ranged from 1.9 to $8.5 \mathrm{~kg}$ (median $4.6 \mathrm{~kg}$ ). The distributions of patient age and weight are shown in Fig 1. No patient had undergone prior pulmonary artery banding, although four patients with associated coarctation of the aorta had undergone neonatal coarctation repair (without pulmonary artery banding) between 1 and 7 weeks earlier. Preoperative assessment consisted of clinical examinations and echocardiography alone in 62 patients $(86 \%)$; the other 10 patients also underwent cardiac catheterization for reasons that included referring physician preference, pulmonary hemodynamic assessment beyond 6 months of age, and associated tetralogy of Fallot or branch pulmonary artery stenosis. AV valve regurgitation assessed by echocardiography was graded as none, trace, mild, moderate, or severe according to standard methods. ${ }^{10}$ Evaluation of follow-up echocardiograms was performed by a cardiologist who was unaware of the study objectives.

The AVSD was Rastelli type A in 53 patients (74\%), type $\mathrm{B}$ in 1 patient (1\%), and type $\mathrm{C}$ in 18 patients $(25 \%) .{ }^{11}$ Trisomy 21 (Down syndrome) was present in 54 patients (75\%), and 6 of the non-Down syndrome patients had other syndromes, including polysplenia $(n=3)$, Ellis-van Kreveld $(n=1)$, Dandy Walker $(n=1)$, and Baller-Gerold $(n=1)$. Associated anomalies are summarized in Table I. Preoperative AV valve regurgitation was moderate or severe in 17 patients (24\%; Table II). On the basis of risk factors for poor outcome identified in previous studies, ${ }^{1-5}$ patients with any of the following were grouped and categorized as having "complex AVSD" for purposes of data analysis: unbalanced AVSD, doubleorifice left AV valve, single papillary muscle, or severely
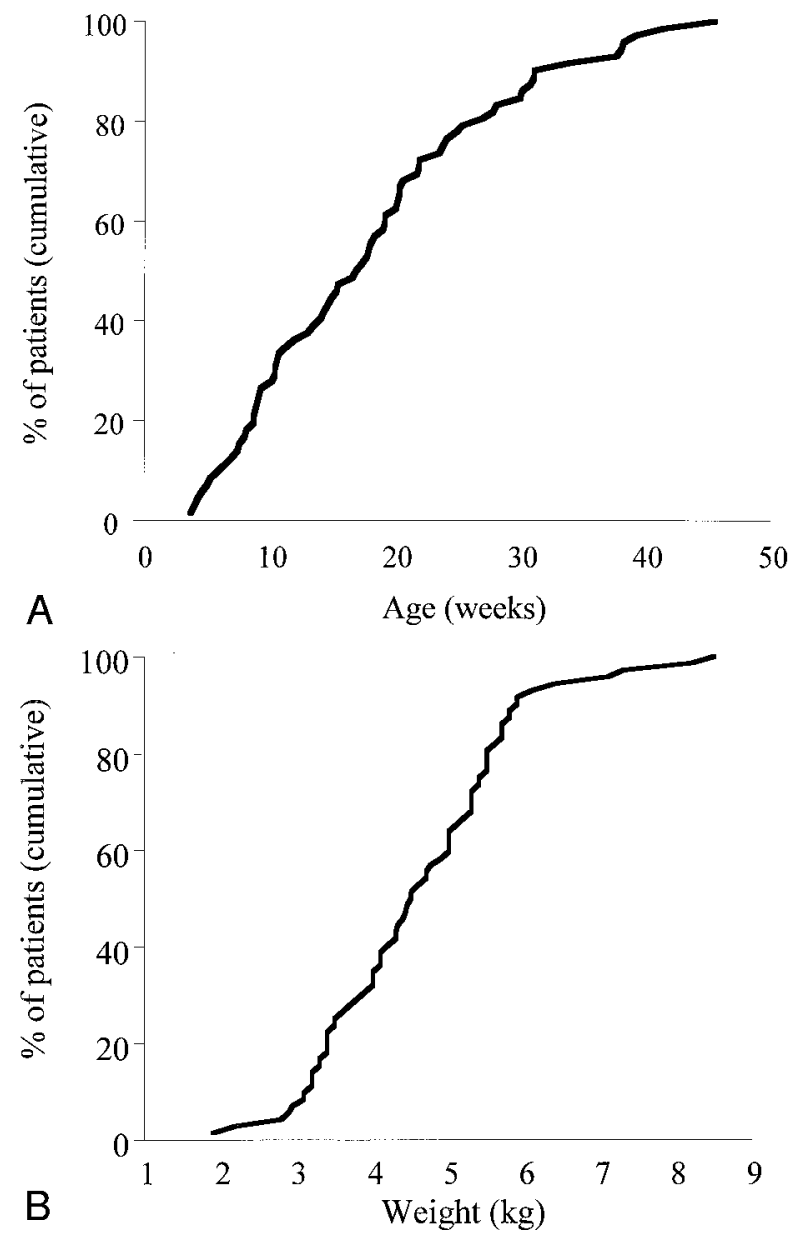

Fig. 1. Distribution of ages (A) and weights (B) at repair among 72 infants undergoing primary repair of complete AVSD in infancy.

dysplastic left AV valve. Factors correlating with moderate preoperative regurgitation included non-Down syndrome AVSD (odds ratio $[\mathrm{OR}]=0.25,95 \%$ confidence interval $[\mathrm{CI}]: 0.08$ to $0.80 ; p=0.016)$ and unbalanced AVSD $(\mathrm{OR}=5.3 ; 95 \% \mathrm{CI}: 1.1$ to $26.8 ; p=0.03)$.

Operative procedures. Patients were placed on cardiopulmonary bypass with aortic and bicaval cannulation, with moderate hypothermia and cold cardioplegic arrest. The AVSD was approached through a right atriotomy. A single pericardial patch, harvested at the beginning of surgery and fixed in glutaraldehyde, was used to repair the entire septal defect in all patients. In all patients the bridging leaflets were divided. The interventricular component of the defect was first closed, with interrupted pledget-supported 5-0 nonabsorbable sutures or continuous 5-0 polypropylene suture. When the level of the AV valve orifice was reached, the divided valve leaflets were sewn to the patch with interrupted nonabsorbable doubly pledget-supported sutures. Closure of the cleft in the newly created left AV valve was performed with interrupted $5-0,6-0$, or 7-0 polypropylene sutures, which were 
Table II. Atrioventricular valve regurgitation (AVVR) among 72 patients* undergoing repair of complete AVSD in infancy

\begin{tabular}{|c|c|c|c|c|c|c|c|}
\hline \multirow[b]{2}{*}{$A V V R$} & \multirow{2}{*}{$\begin{array}{c}\text { Preoperative } \\
(\%)\end{array}$} & \multicolumn{2}{|c|}{ Intraoperative $T E E_{\dagger} \dagger$} & \multicolumn{2}{|c|}{ Discharge } & \multicolumn{2}{|c|}{ Follow-up } \\
\hline & & $L A V V(\%)$ & $R A V V(\%)$ & $L A V V(\%)$ & $R A V V(\%)$ & $L A V V(\%)$ & $R A V V(\%)$ \\
\hline None/trace & $22(31)$ & $55(77)$ & $63(87)$ & $52(73)$ & $58(82)$ & $54(76)$ & $59(83)$ \\
\hline Mild & $33(46)$ & 14 (19) & $9(13)$ & $16(23)$ & $12(17)$ & 14 (19) & $12(17)$ \\
\hline Moderate & $14(19)$ & $3(4)$ & 0 & $3(4)$ & $1(1)$ & $3(4)$ & 0 \\
\hline Severe & $3(4)$ & 0 & 0 & 0 & 0 & 0 & 0 \\
\hline
\end{tabular}

$A V S D$, Atrioventricular septal defect; $T E E$, transesophageal echocardiography; $L A V V$, left atrioventricular valve; $R A V V$, right atrioventricular valve.

*Due to one early death, data are available for 71 patients at discharge and on follow-up.

$\dagger$ In two patients weighing $<2.5 \mathrm{~kg}$, intraoperative epicardial echocardiography was performed instead of TEE.

usually carried out to the first order chordae tendineae (complete closure), although fewer sutures were placed (partial closure) in certain cases. Complete closure of the left AV valve was performed in 61 patients $(85 \%)$. Partial closure was performed in 10 patients with circumstances in which complete closure would have resulted in a restrictive valve orifice, including non-Down syndrome $(n=4)$, unbalanced AVSD $(n=3)$, double-orifice left AV valve $(n=2)$, and single left papillary muscle $(n=1)$. In the other patient with a single left papillary muscle, the left AV valve was not closed. Commissural annuloplasty was performed to reduce central regurgitation of the left AV valve in 18 patients $(25 \%)$ and of the right valve in 2 patients $(3 \%)$. After resuspension and adjustment of the leaflets, the pericardial patch was used to close the atrial component of the defect (including the secundum defect, when present) with running 5-0 polypropylene suture.

After closure of the atriotomy and discontinuation of bypass, transesophageal echocardiography was performed in all patients weighing $2.5 \mathrm{~kg}$ or more; patients weighing less than $2.5 \mathrm{~kg}$ underwent intraoperative epicardial echocardiography. If AV valve regurgitation was mild and there existed a good possibility of reducing regurgitation, bypass was recommenced and further valve repair was performed. We returned 10 patients (14\%) to bypass to revise the valve repair. Annuloplasty was performed in four of these cases, and valve regurgitation was reduced to mild or less in all except for one patient who had an extremely dysplastic left AV valve with short chordae and thick, rolled leaflets.

All associated anomalies were repaired completely. Total perfusion time was $161 \pm 52$ minutes, and aortic crossclamp time was $107 \pm 42$ minutes. Circulatory arrest was not used.

Data analysis. Patient records were reviewed retrospectively, and follow-up was obtained by direct contact with referring cardiologists. SPSS for Windows version 6.01 (SPPS Inc., Chicago, Ill.) was used to perform statistical calculations. Data are expressed as median and range or mean \pm standard deviation. ORs are presented with $95 \%$ CI. $\chi^{2}$ analysis was used to compare dichotomous variables. Nonparametric analysis involving ordinal variables was conducted with the Wilcoxon signed-rank test. Independent samples $t$ test was used for comparison of means. Kaplan-Meier and Cox proportional hazards models were used for actuarial survival analysis and analysis of freedom from reoperation. Age was analyzed as a contin- uous variable and as four sets of dichotomous variables, with division points for dichotomous analysis set at less than 2 months, less than 3 months, less than 4 months, and less than 6 months. AV valve regurgitation (at all time points measured) was analyzed as both an ordinal variable with each degree of regurgitation treated as a discrete value and as a dichotomous variable with less than mild and mild as the two values. Factors significantly associated with AV valve regurgitation $(p<0.05)$ were entered into multivariable analysis with multiple logistic regression.

\section{Results}

Early results. There was one hospital death $(1.4 \%)$. This occurred in a 45-day-old patient with a single papillary muscle who was placed back on bypass for valve revision. After a stable initial course, the patient experienced arrest in association with removal of a transthoracic left atrial line on postoperative day 1 and was placed on extracorporeal membrane oxygenation. The patient died 3 days later. No patient required reoperation for any reason, and no other patient was placed on extracorporeal circulatory support. Five patients had a transient junctional escape rhythm, and one patient experienced transient complete AV block. All of these patients were in normal sinus rhythm by the time they were transferred out of the intensive care unit. Median postoperative hospital stay was 7 days (range 4 to 48 days).

AV valve function in the operating room after removal from bypass (assessed by transesophageal echocardiography) and before hospital discharge are summarized in Table II (Fig 2). Factors associated with mild left AV valve regurgitation at discharge are summarized in Table III. There was no significant change in valve function at discharge relative to the findings of intraoperative transesophageal echocardiography. On intraoperative transesophageal echocardiography, no patient had severe left AV valve regurgitation and three patients (4\%) 
had moderate regurgitation. One of these patients had a double-orifice left AV valve with a large cleft that could not be closed; the second had a severely unbalanced right dominant AVSD with short chordae tethering a dysmorphic left AV valve, and repair options were limited by the small left component of the AV valve; the third patient had a severely dysplastic left AV valve with thickened, rolled leaflets and short chordae. No patient progressed to moderate regurgitation between intraoperative and discharge echocardiographic evaluation. There were four tiny residual ventricular septal defects on intraoperative transesophageal echocardiography (5\%); all of these were still present on discharge echocardiography, and one very small apical muscular ventricular septal defect was also detected on discharge echocardiography.

\section{Follow-up}

Follow-up was complete in all patients and ranged from 3 to 57 months (median 24 months). There was one late death, 13 months postoperatively, in a patient with Ellis-van Creveld syndrome (including chest wall and lung hypoplasia) who had had three episodes of preoperative cardiopulmonary arrest from which he had been adequately resuscitated. An autopsy was not performed, but the cause of death was respiratory failure related to his chest wall and pulmonary hypoplasia. Overall survival was $96 \%$ from 2 to 4 years.

Five patients required reoperations for left AV valve regurgitation or left ventricular outflow tract obstruction (Table IV), including two of the patients with moderate $\mathrm{AV}$ valve regurgitation at discharge echocardiography. All of the patients were at high risk for reoperation because of morphologic features. Both patients who required reoperation for left AV valve regurgitation had severely dysplastic valve tissue, one had an unbalanced AVSD, and both had moderate regurgitation at discharge. All three of the patients who required reoperation for subaortic obstruction had inadequate left $\mathrm{AV}$ valve tissue associated with non-Down syndrome AVSD. Actuarial freedom from reoperation on the left AV valve was $100 \%$ among patients without complex AVSD and $85 \%$ among patients with complex AVSD $(p>0.45)$ from 2 to 4 years postoperatively (Fig 3). There were no significant predictors of shorter duration to reoperation. Actuarial freedom from left ventricular outflow tract reoperation was $96 \%$ at 1 year and $92 \%$ from 2 to 4 years. Among patients without Down syndrome, freedom from

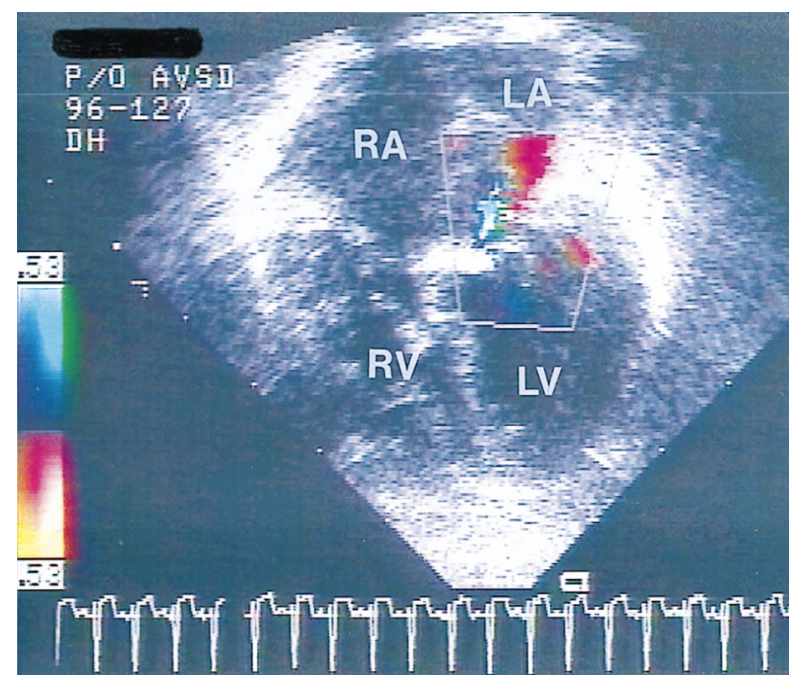

Fig. 2. Echocardiography performed before discharge in a $2.9 \mathrm{~kg}$ neonate who underwent complete repair of a type C AVSD, with complete cleft closure and annuloplasty. Apical four-chamber view in systole shows trivial regurgitation (blue jet) from the left ventricle $(L V)$ into the left atrium $(L A)$. $R A$, Right atrium; $R V$, right ventricle.

reoperation on the left ventricular outflow tract was $71 \%$ at 3 years, although non-Down AVSD was not a statistically significant predictor of earlier outflow tract reoperation.

$\mathrm{AV}$ valve function at follow-up echocardiography is summarized in Table II. There was essentially no change from discharge echocardiography. Factors associated with left $\mathrm{AV}$ valve regurgitation $\geq$ mild at follow-up are summarized in Table III. Age and weight had no relationship to left or right AV valve regurgitation at follow-up, as either continuous or dichotomous variables.

\section{Discussion}

Since the first successful repair of complete AVSD by Lillehei and associates, ${ }^{12}$ surgical results have steadily improved and the age at repair has gradually decreased, ${ }^{1-4}$ with several centers reporting surgical mortality rates of $<5 \%$ after repair in infancy in recent years. ${ }^{1,2,4,5}$ Factors complicating repair in older patients include pulmonary vascular obstructive disease and distortion of the AV valve, both of which progress over time. ${ }^{13-17}$ Though the relationship between age and pulmonary vascular disease has been investigated extensively, ${ }^{6,13-15}$ few data have been published regarding whether repair early or late in infancy has any bearing on valve function. ${ }^{5}$ Concerns over repairing AVSD early in 
Table III. Variables associated with postoperative left atrioventricular valve regurgitation ( $\geq$ mild)

\begin{tabular}{|c|c|c|c|}
\hline Variable & Odds ratio* $(95 \%$ CI $)$ & Univariable $p$ value & Multivariable $p$ value \\
\hline \multicolumn{4}{|l|}{ Discharge echocardiography } \\
\hline Incomplete or no cleft closure & $4.8(1.2-18.7)$ & 0.016 & 0.007 \\
\hline Complex AVSD & $3.7(1.1-12.5)$ & 0.027 & NS \\
\hline Preoperative AVVR ( $\geq$ mild) & $4.0(1.1-15.4)$ & 0.035 & 0.03 \\
\hline Trisomy 21 & $0.34(0.12-1.1)$ & 0.066 & NS \\
\hline Longer CPB time (min) & & 0.024 & NS \\
\hline \multicolumn{4}{|l|}{ Follow-up echocardiography } \\
\hline Complex AVSD & $3.1(0.94-10.4)$ & 0.055 & NS \\
\hline Return to $\mathrm{CPB}$ & $8.6(1.6-45.2)$ & 0.007 & 0.007 \\
\hline
\end{tabular}

$A V S D$, Atrioventricular septal defect; $A V V R$, atrioventricular valve regurgitation; $C P B$, cardiopulmonary bypass.

*Odds ratios listed are for univariable analysis.

Table IV. Patients requiring reoperation after repair of complete AVSD in infancy

\begin{tabular}{|c|c|c|c|}
\hline $\begin{array}{l}\text { Age at } \\
\text { repair }\end{array}$ & $\begin{array}{l}\text { Duration } \\
\text { after repair }\end{array}$ & Reoperation procedures & Diagnostic variables \\
\hline 65 days & $22 \mathrm{mo}$ & Subaortic stenosis resection & Non-Down syndrome, subaortic stenosis ( $90 \mathrm{~mm} \mathrm{Hg}$ gradient) \\
\hline $5.5 \mathrm{mo}$ & $23 \mathrm{mo}$ & Subaortic stenosis resection & Non-Down syndrome, subaortic stenosis ( $80 \mathrm{~mm} \mathrm{Hg}$ gradient) \\
\hline 36 days & $4 \mathrm{mo}$ & LAVV replacement & $\begin{array}{l}\text { Down syndrome, severely dysplastic LAVV, moderate } \\
\text { regurgitation }\end{array}$ \\
\hline 34 days & $12 \mathrm{mo}$ & Subaortic stenosis resection & $\begin{array}{l}\text { Non-Down syndrome (polysplenia), subaortic stenosis } \\
\text { (60 mm Hg gradient) }\end{array}$ \\
\hline $3.1 \mathrm{mo}$ & $13 \mathrm{mo}$ & $\begin{array}{l}\text { LAVV repair, commissurotomy for } \\
\text { partially fused bicuspid aortic valve }\end{array}$ & $\begin{array}{l}\text { Unbalanced AVSD, severely dysplastic LAVV } \\
\text { with moderate regurgitation, valvar aortic stenosis } \\
\text { (55 mm Hg gradient) }\end{array}$ \\
\hline
\end{tabular}

$\overline{A V S D}$, Atrioventricular septal defect; $L A V V$, left atrioventricular valve.

infancy are based on the extremely delicate and fragile AV valve tissue. Any delay on this basis must be balanced against increased morbidity from continuing failure to thrive, respiratory infections, and pulmonary vascular disease. ${ }^{9}$ Since 1992 , we have taken the approach of repairing complete AVSD primarily early in infancy rather than continuing with prolonged medical management. Nevertheless, during this time period we have performed primary complete repair in 15 infants who were referred for surgery beyond 6 months of age. This experience provides the opportunity to review a large cohort of patients ranging in age from early to late infancy in an attempt to elucidate the relationship between age at repair and overall outcomes, especially AV valve function.

During this time period at our institution, there was a single early death $(1.4 \%)$ and no early reoperations. There was one late death, and five patients have undergone reoperation for left AV regurgitation $(n=2)$ and/or left ventricular outflow tract obstruction $(n=4)$. Three patients were discharged from the hospital with moderate AV valve regurgitation; two of these were the patients who later underwent reoperation for left AV valve regurgitation. The rates of progression of $\mathrm{AV}$ valve regurgitation were very low for both the left and right valves, and there were no significant predictors of either mild $A V$ valve regurgitation or progression of regurgitation, including age and weight. These results suggest that repair in early infancy carries very little risk of poor outcome and has no adverse effect on valve function.

Technical factors have been a primary focus in a number of recent reports on AVSD repair. ${ }^{1-8}$ In neonates and very young infants the question of single versus double patch repair of AVSD is unresolved. ${ }^{1-6}$ Excellent results have been demonstrated with both techniques, ${ }^{1-8}$ and we think that the choice primarily comes down to personal preference. It has been our policy to perform single patch repair, with complete closure of the left AV valve cleft except when this will restrict left ventricular inflow. In several recent series, incomplete closure of the cleft was found to correlate with reoperation for failure of the left AV valve., ${ }^{2,17}$ Although too few of our patients have required reoperation on the $\mathrm{AV}$ valves to determine whether incomplete cleft closure is a 
risk factor for reoperation, the strongest predictor of mild left AV valve regurgitation on discharge echocardiography was incomplete or no cleft closure. Whether the cleft can be closed completely depends primarily on the presence or absence of complicating morphologic factors such as single left papillary muscle, double-orifice valve, unbalanced AVSD, dysplastic valve leaflets, and Down syndrome. Young age and small size had no relation to cleft closure among our patients.

Aside from patients in this series with incomplete cleft closure, those who had moderate postoperative left AV valve regurgitation, who required reoperation, or who died had complicating morphologic features that placed them at highest risk for such outcomes in a number of recent studies. For example, double-orifice left AV valve has been associated with early mortality, ${ }^{1}$ reoperation for valve regurgitation, ${ }^{2}$ and significant postoperative regurgitation. ${ }^{5}$ Similarly, non-Down syndrome AVSD has been associated with significant postoperative left AV valve regurgitation ${ }^{3}$ and with reoperation for this reason. ${ }^{5}$ Significant early postoperative left AV valve regurgitation has been found to correlate with mortality, ${ }^{1,2}$ and reoperation for valve regurgitation. $1,2,5$

Although dysplastic AV valve leaflets may be present from early in life, dysmorphic and poorly functional leaflets in AVSD may also be the result of damage sustained from prolonged turbulence in the setting of an unrepaired defect. ${ }^{2,5}$ Michielon and associates $^{5}$ recently reported that patients of a younger age ( $<4$ months) at AVSD repair had significantly less AV valve incompetence both preoperatively and postoperatively. Although we did not find the same correlation in our series, we agree that the AV valves tend to be thickened in older infants. The effect of thickened valves on long-term valve function is unknown. Among our patients, however, there was no significant progression of valve regurgitation at medium-term follow-up regardless of age at repair.

Aside from the benefits of early symptomatic improvement and a lower likelihood of pulmonary vascular complications, there are other benefits of repair in early infancy. Because the risk of pulmonary vascular obstructive disease is much less common in early infancy, ${ }^{6,13,14}$ it is possible to perform complete repair without cardiac catheterization, which is only indicated in patients at high risk for pulmonary vascular disease or those with complicated anatomy that cannot be evaluated satisfacto-

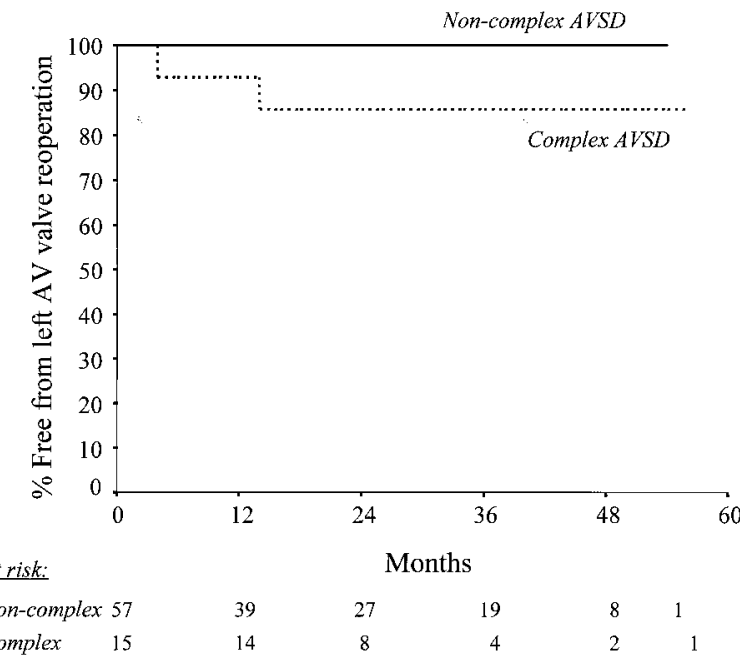

Fig. 3. Actuarial freedom from reoperation for AV valve dysfunction after primary repair of complete AVSD in infancy. The difference between patients with and without complex AVSD was not statistically significant.

rily with echocardiography (such as branch pulmonary artery stenosis). In infants, echocardiography has been shown to be consistently adequate for the diagnosis and definition of AVSD. ${ }^{18}$ The morphologic detail that can be obtained with two-dimensional echocardiography allows for optimal preoperative definition of the common AV valve leaflets and subvalvular apparatus in AVSD. ${ }^{10}$

Also, repair in neonates and infants can be performed without deep hypothermic circulatory arrest. Aside from the usual advantages of avoiding or minimizing neurologic insult when operating without circulatory arrest, this provides more time for repair, which facilitates greater technical precision. Without the time pressure of circulatory arrest, meticulous care can be taken to achieve an optimal repair.

Repair of complete AVSD can be achieved with excellent early results in neonates and young infants. Age and weight at repair in infancy do not appear to have a significant influence on intermediate-term valve function. Elective repair in early infancy does not increase the risk of mortality or poor functional outcome and should be considered in almost all patients. Delaying surgery until later in infancy only increases the risks of persistent failure to thrive, pulmonary vascular disease, and damage to the AV valve tissue. Therefore, we currently recommend elective repair of complete AVSD for patients who 
are 2 to 3 months of age and earlier in symptomatic patients.

\section{REFERENCES}

1. Hanley FL, Fenton KN, Jonas RA, et al. Surgical repair of complete atrioventricular canal defects in infancy: twentyyear trends. J Thorac Cardiovasc Surg 1993;106:387-97.

2. Bando K, Turrentine MW, Sun K, et al. Surgical management of complete atrioventricular septal defects: a twentyyear experience. J Thorac Cardiovasc Surg 1995;110:1543-54.

3. Tweddell JS, Litwin SB, Berger S, et al. Twenty-year experience with repair of complete atrioventricular septal defects. Ann Thorac Surg 1996;62:419-24.

4. Capouya ER, Laks H, Drinkwater DC, Pearl JM, Milgalter E. Management of the left atrioventricular valve in the repair of complete atrioventricular septal defects. J Thorac Cardiovasc Surg 1992;104:196-203.

5. Michielon G, Stellin G, Rizzoli G, et al. Left atrioventricular valve incompetence after repair of common atrioventricular canal defects. Ann Thorac Surg 1995;60:S604-9.

6. Backer CL, Mavroudis C, Alboliras ET, Zales VR. Repair of complete atrioventricular canal defects: results with the two-patch technique. Ann Thorac Surg 1995;60:530-7.

7. Alexi-Meskishvili V, Ishino K, Dähnert I, et al. Correction of complete atrioventricular septal defects with the doublepatch technique and cleft closure. Ann Thorac Surg 1996;62: 519-25.

8. Ebels T. Surgery of the left atrioventricular valve and of the left ventricular outflow tract in atrioventricular septal defects. Cardiol Young 1991;1:344-55.

9. Samánek M. Prevalence at birth, "natural" risk and survival with atrioventricular septal defect. Cardiol Young 1991;1: 285-9.

10. Silverman NH. Pediatric echocardiography. Baltimore, MD: Williams \& Wilkins; 1993. p.143-56.

11. Rastelli GC, Kirklin JW, Titus JL. Anatomic observations on complete form of persistent common atrioventricular canal with special reference to atrioventricular valves. Mayo Clin Proc 1966;41:296-308.

12. Lillehei CW, Cohen M, Warden HE, Varco RL. The directvision intracardiac correction of congenital anomalies by controlled cross-circulation: results in thirty-two patients with ventricular septal defects, tetralogy of Fallot, and atrioventricularis communis defects. Surgery 1955;38:11-29.

13. Alt B, Shikes RH. Pulmonary hypertension in congenital heart disease: irreversible vascular changes in young infants. Pediatr Pathol 1983;1:423-34.

14. Matsuda H, Hirose H, Nakano S, et al. Postoperative changes of pulmonary vascular resistance in patients with complete atrioventricular canal defect: relation to the age at primary repair. Jpn Circ J 1984;48:1081-6.

15. Yamaki S, Yasui $\mathrm{H}$, Kado $\mathrm{H}$, et al. Pulmonary vascular disease and operative indications in complete atrioventricular canal defect in early infancy. J Thorac Cardiovasc Surg 1993;106:398-405.

16. Abbruzzese PA, Livermore J, Sunderland CO, et al. Mitral repair in complete atrioventricular canal: ease of correction in early infancy. J Thorac Cardiovasc Surg 1983;85:388-95.

17. Han L, Kang SU, Park SC, Ettedgui JA, Neches WH.
Long-term left atrioventricular valvular function following surgical repair of atrioventricular septal defect. Cardiol Young 1995;5:230-7.

18. Zellers TM, Zehr R, Weinstein E, Leonard S, Ring WS, Nikaidoh H. Two-dimensional and Doppler echocardiography alone can adequately define preoperative anatomy and hemodynamic status before repair of complete atrioventricular septal defect in infants $<1$ year old. J Am Coll Cardiol 1994;24:1565-70.

\section{Discussion}

Dr. James A. Alexander (Gainesville, Fla.). This is an absolutely spectacular series of AV canals. Clearly your results are to be envied. All of us are pushing the age down for time of repair. It was intriguing that your mean hospital stay was 7 days. I do not think I can get a patient with canal Down syndrome out of the hospital with a cold in that period of time. I certainly would agree that the non-Down syndrome canals are a more difficult and challenging population, and you must be commended on the fact that $73 \%$ of your patients had none to trace mitral insufficiency at time of discharge. There are several questions that I would like to ask.

You had seven patients who were noted to have unbalanced canals. What is your limit of AV valve split by echocardiography that you would contemplate completing a repair-40/60, 60/40, right/left, left/right, 70/30, 30/70? We at the University of Florida have not had good results with splits that were 70/30.

Have you seen problems with the use of pericardium for the ventricular portion of the repair in long-term followup, that is, shrinkage or enlargement?

Even at young ages the pulmonary vasculature is still reactive. Did you measure pulmonary artery pressures after surgery? And if you did, was there a significant difference in the transient pulmonary crisis that occurs in the postoperative period in the 2- to 3 -month-old patient as opposed to the 5- to 6-month-old patient?

Six children had AV canal-tetralogy of Fallot complex repaired. Do the small pulmonary arteries or small PA anulus affect your timing of repair?

Your recommendation was to complete these repairs electively at 6 to 8 weeks when only about $18 \%$ of your group fell within that time frame. Could you elaborate a little further?

Dr. Yasunaru Kawashima (Osaka, Japan). As many infants with AVSDs die before they become 1 or 2 years of age, early surgery is definitely recommendable. I quite agree with the conclusion reported.

However, one thing I am concerned about is that the septal patch you use to close the defect does not grow. So that when anteroposterior diameter of the common AV valve is fixed when patient is very young, it will make more deformity of $\mathrm{AV}$ valve when they grow up to the adult size, not to the child size, than when it is fixed at the older age. Because your follow-up period is 4 to 5 years, you may not have the answer for this question, but I would like to know your opinion on this matter.

Dr. Gerhard Ziemer (Tuebingen, Germany). You suggested 4 to 8 weeks of age as being the best time to repair. What about the idea to band in selected cases of complete AV canal? 
I have found the AV canal deaths to be almost exclusively in the first month of life. Reasons included technical problems caused by the more friable valve tissue then, even more if the patient had been a premature baby. Once a suture is torn out in these valves, even directly in the operation, it is tough to again repair it without compromising valve function. So I still agree with the idea of early repair using the single patch technique in infancy. In most of the patients requiring surgery as a neonate, however, I first band to come back for repair within the first 6 months of life. If, however, symptomatic coarctation is there, I always would repair it simultaneously through a transsternal approach with repair at any age. Could you give these ideas any consideration, or am I just wrong?

Dr. Thomas L. Spray (Philadelphia, Pa.). I noticed that the incidence of subaortic stenosis seemed to be relatively high for a small series of patients. Were you able to see any correlation between the development of subaortic stenosis and the indication for operation at a young age? Were the few patients in your series who were operated on under 2 months of age operated on because they had very large left-to-right shunts and might have had a predisposition or an underlying subaortic stenosis that was unrecognized until the canal was repaired? You suggest that we should now electively do these repairs at 4 to 8 weeks, but yours is a retrospective series. Therefore what were the indications for repair at a very young age in this series?

Dr. Reddy. I thank all of the discussants for their comments, and I will address the questions in the order they occurred.

Dr. Alexander, regarding the unbalanced AVSDs, we generally go by roughly the same principle, about $60 \%$ to $40 \%$. However, at our institution Norman Silverman has looked at certain indices of making a decision; these findings will be published soon. But in general I would say $60 \%$ to $40 \%$ would be a cutoff.

We have used a pericardial patch in all these patients, and at medium-term follow-up at our institute, there have been no issues regarding AV valve insufficiency. I think more long-term data comes from other institutions that have used pericardial patch, for example, Boston Children's, and I am not aware of any publication that shows detrimental results from the use of the pericardial patch.

Earlier in our experience we routinely monitored pulmonary artery pressures. We subsequently abandoned that because, number one, we did not see many pulmonary hypertensive crises in patients repaired very early in life. Number two, we also had transesophageal echocardiography with which we could do a very good job of repairing these valves, so residual lesions were not an issue. For these two reasons and the potentially associated morbidity of pulmonary arterial line, we abandoned the use. We still do use pulmonary arterial lines in older infants or patients who undergo surgery beyond infancy.

Regarding the timing of repair in patients with associated tetralogy of Fallot, we prefer to perform complete repair in infancy. We have often electively used homograft pulmonary valves in these patients because significant pulmonary insufficiency can adversely affect the AV valve repair and hence the outcome. Pulmonary artery size itself has not been a problem in our experience.

Again, about the age of repair, I agree that only $20 \%$ of our patients are under 2 months of age. The current practice is to electively repair between 4 to 8 weeks.

If you look at this patient population, a number of these patients would have had previous hospital admissions for pulmonary tract infections or for congestive heart failure. Often they are put on surgical schedule when the cardiologists have exhausted their medical management. Instead of adopting that approach, and to avoid multiple hospital admissions, I think the option of elective repair in early infancy is worth exploring.

Dr. Kawashima, regarding the pericardial patch and growth, it certainly is intuitive to say that pericardial patch fixes the AV valve orifice at least from the septal side; however, the rest of the anulus seems to compensate for this. As far as I am aware, to date, there is no publication that shows, even in the long term, that using one patch or the other has resulted in more AV valve problems at a younger age.

If we look at the patients who underwent repair very early in infancy and follow them as late as 56 months, that is, about 5 years, we can draw some conclusions. The weight of these patients would triple by 1 year of age, and by 5 years their weight would have increased by at least eight- or tenfold. During a rapid spurt of growth any distortion should show up, and if it has not shown up, it seems unlikely that further deterioration will occur in the long term. But the final word is not returned yet.

Dr. Ziemer, regarding pulmonary artery banding, I think it is an option that some centers might still elect to do. However, integrity of the AV valve has not been a question in our experience. If you look at our data more closely in the paper, you will see that our cardiopulmonary bypass times are probably a little longer than you might see. We take time to repair the valve very meticulously. I think that is the key to getting the successful repair.

If there is a coarctation of the aorta associated with AV valve septal defects, we have elected to repair the coarctation first from the side and a few days later to repair the AVSD during the same admission. I think the only indication for currently performing pulmonary artery banding would be an active respiratory syncytial virus infection. Something else might come up, but we have not banded anybody so far.

Dr. Spray, regarding subaortic stenosis, we looked at this to determine whether subaortic stenosis was related to the age at repair, and it was not. In our earlier experience, the indication for repair was definitely failure to thrive or congestive heart failure, but currently these repairs are electively performed.

\section{Appendix}

Variables analyzed for correlation with AV valve function and postoperative events and survival

\section{Demographic and diagnostic}

Age (continuous, $<2$ months, $<3$ months, $<4$ months, $<6$ months)

Weight 
Rastelli type ${ }^{10}$

Trisomy 21

Unbalanced AVSD

Double-orifice left AV valve

Single papillary muscle

Severely dysplastic left AV valve (a qualitative intraoperative assessment made on the basis of severe thickening, rolling, and/or poor mobility)

Multiple ventricular septal defects

Other anomalies (includes any of the other anomalies listed in Table I)
Complex AVSD (patients having any of the following: unbalanced AVSD, double-orifice left AV valve, single papillary muscle, or severely dysplastic left AV valve)

\section{Operative}

Cardiopulmonary bypass time

Aortic crossclamp time

Incomplete cleft closure

Return to bypass for valve revision

Left AV valve annuloplasty

Preoperative AV valve regurgitation (mild, moderate) 